\title{
Effectiveness of interspinous implant surgery in patients with intermittent neurogenic claudication: a systematic review and meta-analysis
}

\author{
Wouter A. Moojen • Mark P. Arts • \\ Ronald H. M. A. Bartels • Wilco C. H. Jacobs • \\ Wilco C. Peul
}

Received: 24 February 2011 / Accepted: 31 May 2011/Published online: 11 June 2011

(C) The Author(s) 2011. This article is published with open access at Springerlink.com

\begin{abstract}
Introduction Despite an increasing implantation rate of interspinous process distraction (IPD) devices in the treatment of intermittent neurogenic claudication (INC), definitive evidence on the clinical effectiveness of implants is lacking. The main objective of this review was to perform a meta-analysis of all systematic reviews, randomized clinical trials and prospective cohort series to quantify the effectiveness of IPDs and to evaluate the potential sideeffects.

Methods Data from all studies prospectively describing clinical results based on validated outcome scales and reporting complications of treatment of patients with INC with IPD placement. We searched MEDLINE, EMBASE, Web of Science, Cochrane (CENTRAL), CINAHL, Academic Search Premier, Science Direct up to July 2010. Studies describing patients with INC caused by lumbar stenosis, reporting complication rate and reporting based
\end{abstract}

W. A. Moojen $(\bowtie) \cdot$ W. C. H. Jacobs · W. C. Peul

Department of Neurosurgery, Leiden University Medical Center,

Albinusdreef 2, 2300 RC Leiden, The Netherlands

e-mail: w.a.moojen@lumc.nl

W. C. H. Jacobs

e-mail: w.c.h.jacobs@lumc.nl

W. C. Peul

e-mail: w.c.peul@lumc.nl

W. A. Moojen - M. P. Arts · W. C. Peul

Department of Neurosurgery, Medical Center Haaglanden,

The Hague, The Netherlands

e-mail: m.arts@mchaaglanden.nl

R. H. M. A. Bartels

Department of Neurosurgery, University Medical Hospital,

Nijmegen, The Netherlands

e-mail: r.bartels@nch.umcn.nl on validated outcome scores, were eligible. Studies with only instrumented IPD results were excluded.

Results Eleven studies eligible studies were identified. Two independently RCTs and eight prospective cohorts were available. In total 563 patients were treated with IPDs. All studies showed improvement in validated outcome scores after 6 weeks and 1 year. Pooled data based on the Zurich Claudication Questionnaire of the RCTs were more in favor of IPD treatment compared with conservative treatment (pooled estimate 23.2, SD 18.5-27.8). Statistical heterogeneity after pooled data was low (I-squared 0.0, $p=0.930$ ). Overall complication rate was $7 \%$.

Conclusion As the evidence is relatively low and the costs are high, more thorough (cost-) effectiveness studies should be performed before worldwide implementation is introduced.

Keywords Degenerative $\cdot$ Lumbar spinal - Stenosis . IPD · Effectiveness · Meta-analysis · Complications

\section{Introduction}

Intermittent neurogenic claudication (INC) is a complex of symptoms, the most important being leg pain and numbness (frequently in both legs) with possibly associated back pain [1-4]. The symptoms can be diminished by flexion of the lumbar spine [5-8]. Lumbar spinal arthrosis inducing arthrosis of the facet is associated with INC $[8,9]$. Traditionally, bony decompression of the canal and the lateral recessus seems to be the golden standard in the treatment of INC [3, 4]. There is some evidence that bony decompression is a proven superior therapy compared with non-surgical therapy, such as steroid injections or physiotherapy $[10,11]$. Less invasive strategies have been developed to 
minimize the perioperative damage, such as unilateral laminotomy or endoscopic procedures [12]. Although surgery is frequently offered, detailed outcome results are not available and spine surgeons try to develop innovative less invasive surgical approaches to gain better outcome than the results observed in daily practice.

Parallel to these developments, interspinous implants for interspinous process distraction devices (IPD) have been developed to achieve indirect decompression [13, 14]. The design of the implants aims at limitation of lumbar extension and increasing the interlaminar space of the affected level [15-19]. Nowadays, the technique is widely used. Kyphon Inc. had a worldwide X-STOP ${ }^{\mathrm{TM}}$ net sale, in the first quarter of 2007, of 18.1 million USD. Paradigm Spine Inc. reported in May 2010 a worldwide sale of 13,128 Coflex $^{\text {TM }}$ devices in 2009 [20]. The existing evidence seems to be poor; almost no comparative studies between conventional surgical decompression and surgery with IPD are done [17, 21-24]. Some claim, performing IPD placement in day surgery and with local anesthesia will lower the costs. However, a thorough cost-analysis has never been performed.

The main objective of this systematic review was to evaluate if surgery with IPD is more effective compared with bony decompression in the treatment of patients with INC or at least more effective compared with conservative (e.g. steroid injections) treatment.

\section{Methods}

This systematic review was performed according to the Cochrane systematic review methodology, up-dated by Furlan and Van Tulder and the Meta-analysis of Observational Studies in Epidemiology (MOOSE) criteria [25-27].

\section{Search strategies}

On July 1, 2010, a search of relevant systematic reviews on IPD in the Cochrane Library and, in addition, observational cohort studies (with and without control group), systematic reviews and randomized clinical trials was conducted in MEDLINE, EMBASE, Web of Science, Cochrane (CENTRAL), CINAHL, Academic Search Premier, Science Direct. Keywords used for the search were: interspinous implant surgery, interspinous implants, interspinous distraction devices, interspinous decompression device, interspinous process decompression, intermittent neurogenic claudication, neurogenic claudication, lumbar stenosis, or spinal stenosis. The full search strategy is available upon request from the corresponding author. References of retrieved articles and relevant overview articles were checked to identify additional studies.
Inclusion criteria

Prospective cohort studies, systematic reviews and/or RCTs written in English were considered eligible for inclusion if they fulfilled all of the following:

1. The study population consists of patients with INC caused by lumbar stenosis.

2. Patients with INC without or with degenerative spondylolisthesis to a maximal grade I.

3. One of the treatments consists of non-instrumented IPD for treating symptoms of INC (excluding pedicle screw fixations combined with IPD).

4. A validated outcome score is used to evaluate the outcome after surgery, the Zurich Claudication Questionnaire or the Modified Roland Disability Questionnaire for Sciatica, Oswestry Disability Index, VAS leg and back pain [28-39].

Studies, in which subgroups met our inclusion criteria, were included in our results if the results for these subpopulations were reported separately.

\section{Study selection}

Two reviewers independently applied the inclusion criteria to select potential relevant studies from the titles and abstracts or if necessary the complete publication of the references retrieved by the literature search. Where necessary, a third reviewer was consulted to resolve a disagreement.

\section{Categorization of the relevant literature}

Relevant literature was categorized under three different headers: systematic reviews, RCTs, and prospective cohort studies of high quality. The header 'systematic reviews' describes all systematic reviews. The header ' $R C T$ ' contains all published RCTs on the same intervention comparing IPD with decompression or conservative treatment. Additional prognostic cohort studies were included. The header 'observational cohort studies' contains all prospective cohorts with adequate description of the follow-up period and validated outcome measurements. When, due to lack of evidence, pooling data was not possible a descriptive review would be performed based on RCTs and prospective observational cohort studies.

Methodological quality assessment

Systematic reviews were validated using the steps defined by Furlan and Van Tulder [27, 40]. To identify potential risks of bias of the included RCTs two reviewers independently assessed the methodological quality of each 
RCT according to the Cochrane quality measurements adapted by Furlan and Van Tulder [25, 27, 41, 42]. Each item was scored as "yes", "no", or "don't' know". High quality was defined as a score of $50 \%$ or more on the methodological quality assessment. The Dutch Cochrane Centre Quality Assessment (DCCQA) scale was used for the validation process for observational studies. According to the Dutch Cochrane Centre Quality Assessment scale, a score below six was defined as low methodological quality on the DCCQA scale. A third reviewer could be consulted to solve disagreement between the reviewers.

\section{Data extraction}

Independently, data were extracted by two reviewers. Information was collected on the study population, intervention(s) performed, outcome measures and outcome. The follow-up time was categorized into short-term outcome (6 weeks after intervention) and long-term outcome (at least 1 year). Furthermore, complication rate and device failure (a re-intervention or other surgical technique was necessary) were recorded. Despite the often mentioned spinal process fractures, all other causes for surgical reinterventions were also recorded [43-46].

\section{Outcome measurements}

There are various classifications to describe neurological and functional outcome of patients with intermittent neurogenic claudication. Articles were filtered on presence of one of the four mostly used outcome scales. Firstly, articles were included on the Zurich Claudication Questionnaire (ZCQ), also known as the Brigham Spinal Stenosis Questionnaire and Swiss Spinal Stenosis Questionnaire [35, 38, 39]. The ZCQ scale consists of three subscales: symptom severity, physical function and patient satisfaction. Domain scores ranges from 1 to 5,1 to 4 , and 1 to 4 , respectively. Like in the study of Tuli in 2006, we chose threshold scores for each scale based on prior work [35, 38, 39, 47]. In the symptom severity scale and in the physical function scale the minimal clinically important difference (MCID) is 0.5 $[38,39]$. A mean patient satisfaction score of less than 2.5 has been shown previously to represent a satisfied patient [38, 39]. Secondly, articles were used on the Modified Roland Disability Questionnaire for Sciatica (MRDQ). The 23-points MRDQ is the most widely used patient-assessed measure of health for low back pain and leg pain [29-34, 36]. This questionnaire consists of 23 questions with higher scores indicating increased disability [48]. The Visual Analog Scale (VAS) is one of the most used follow-up measurement tools for back pain and leg pain [49]. This parameter will measure the experienced back and leg pain intensity in the week before visiting the research nurse.
Pain will be assessed on a horizontal $100 \mathrm{~mm}$ scale varying from $0 \mathrm{~mm}$, "no pain", to $100 \mathrm{~mm}$, "the worst pain imaginable" [49]. This parameter has a MCID of two points on a scale of 0 to 10 [50]. Finally, the Oswestry disability index (ODI), where 0 indicates no disability and 100 indicates worst possible disability, was included for our analysis [51]. This parameter has a MCID of 10.0-12.4 points [50, 52, 53].

\section{Data synthesis}

A meta-analysis was performed if two or more RCTs were available with clinical homogeneous patient groups and statistical homogeneous results. When not possible, due to small amount of studies or heterogeneity, a best-evidence synthesis was used. Best-evidence synthesis was performed stratified for studies meeting $50 \%$ or more opposed to those meeting less than $50 \%$ of the quality criteria of the Van Tulder list [27]. The study was only included in the bestevidence synthesis if a comparison was made between the groups (IPD placement vs. conservative treatment or IPD placement vs. surgical decompressive treatment). When meta-analysis or best-evidence synthesis based on RCT is not possible, a data extraction based on observational studies (with or without control group) will be performed. Although a high risk of bias is possible, if possible we performed a data extraction from observational studies based on the "best-of-the-rest" principle.

\section{Results}

\section{Study selection}

The search revealed 253 references. 222 articles were excluded on the basis of the abstract, title and keywords. 20 articles were excluded after reading the complete articles because of the following reasons: the reports did not consist original patient data (4) [17, 23, 54, 55], articles were not written in English (2) [56, 57], there were no outcome results given (9) [24, 58-65], studies with a retrospective study design (5) [43, 66-69]. As a result, only three RCTs and eight prospective cohorts were included for methodological quality assessment in this review (Fig. 1, Flowchart) [17, 21-23, 70-76].

\section{Description of study characteristics}

No systematic reviews could be found. Three reports of randomized clinical trials (RCTs) and eight prospective cohorts were found. Three reports described two RCTs comparing non-operative treatment to treatment with IPD; one observational cohort described IPD treatment versus 
Fig. 1 Flowchart

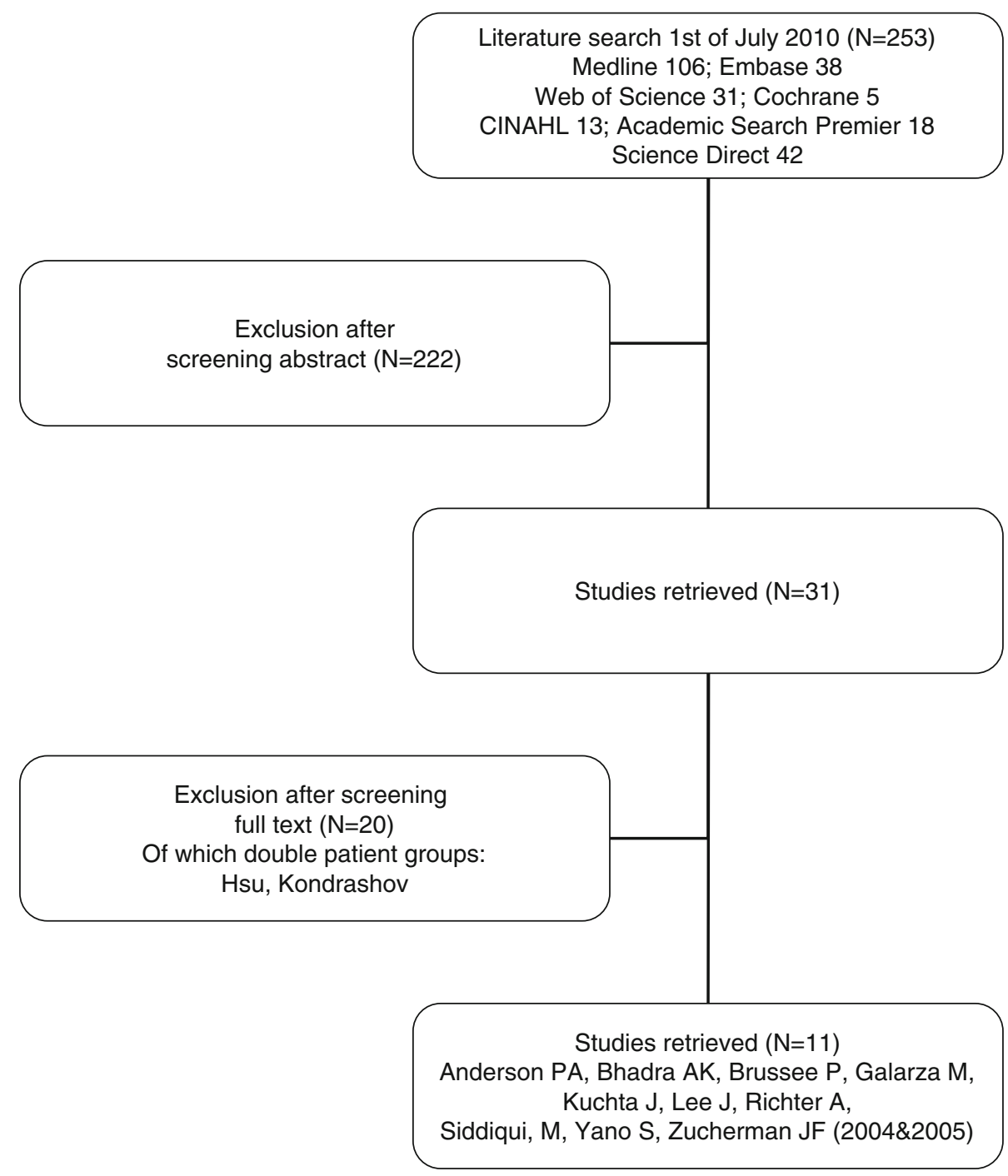

non-operative treatment after bony decompression in both groups; seven cohorts described treatment with IPD only. Two RCTs described the results of the same patient sample. The first study published follow-up data after 1 year and the last published study after 2 years, both are shown in Table $1[17,23]$.

\section{Methodological quality assessment}

The methodological quality of the studies is summarized in Tables 1 and 2. Two reports of one RCT (of the three RCTs) had a methodological quality score of 5 (low quality) and one RCT had a quality of 6 (a high quality study) according to the Furlan and Van Tulder criteria $[25,27]$. Only one observational study had a methodological quality of 6 out of 8 (reflecting high quality) [76], thus the remaining 7 observational studies are of low methodological quality and with high risk of bias [22, 70-75].
Data extraction

In Tables 3, 4 and 5, relevant data on the selected studies is shown with the baseline and postoperative follow-up scores at 6 weeks and 1 year. Two RCTs with different patients samples (the two RCTs of Zucherman were conducted on the same patient sample), Anderson et al. and Zucherman et al. [17, 21], could be used for best evidence synthesis. Both RCTs compared conservative treatment with IPD placement (Fig. 2, meta-analysis). Both studies measured follow-up data on the ZCQ. In the study by Zucherman et al., however, overall success rates and standard deviation (SD) values were not shown. A calculation was made, based on the ZCQ values of symptom severity and physical function ZCQ. SD values were calculated estimated from the SD values of Anderson et al. Both studies favored treatment with IPD placement, pooled ZCQ improvement by 23.2 (SD 18.5-27.8). Statistical heterogeneity after pooled data was low (I-squared $0.0, p=0.930$ ). According 

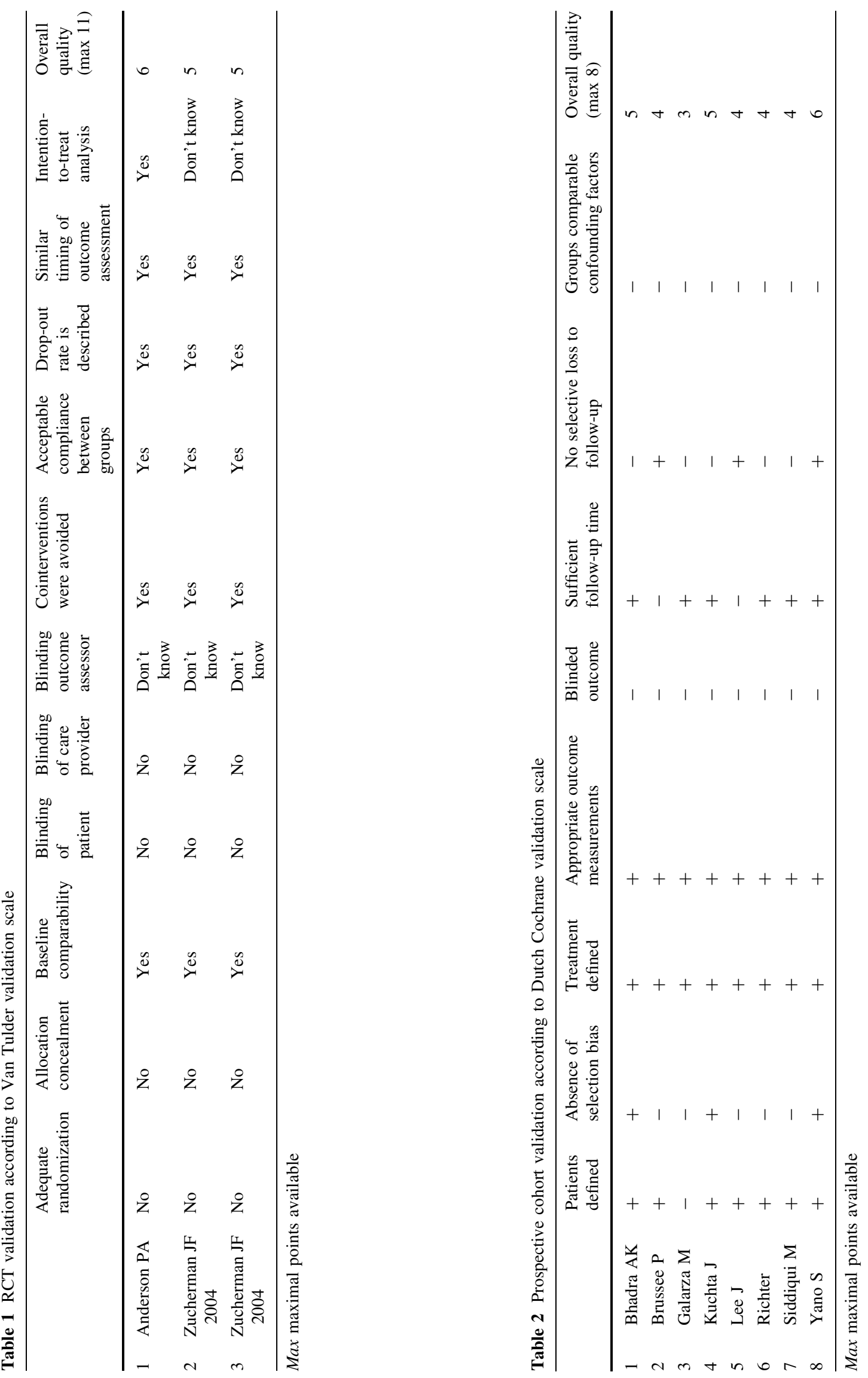


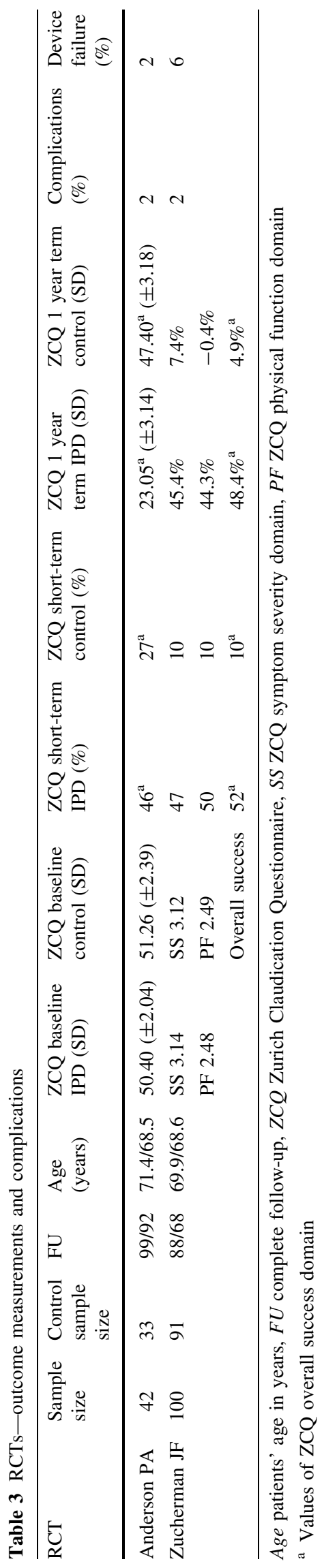

to the statistical heterogeneity, baseline criteria in both studies showed a good clinical homogeneity. Richter et al. [22] compared two surgical decompression cohorts: one group with surgical decompression and no IPD placement, one group with surgical decompression with IPD placement. Both groups showed clinical improvement in the ODI, MRDQ and VAS. At 6 weeks and at 1 year follow-up there were no statistical significantly differences between both groups. The remaining seven prospective cohort studies showed improvement from baseline after treatment with IPD [70-76]. However, these groups did not compare other treatment modalities (such as conservative treatment) with IPD follow-up results. Due to the use of multiple follow-up scales, pooling of data was not possible (Tables 4, 5, prospective cohort studies).

In our search of literature, 563 patients underwent implantation with IPD. Complication rates and device failure rates were available from 513 patients (Table 3, RCT, Tables 4, 5, prospective cohorts). A total of 31 devices failed $(6 \%)$ and had to be replaced or were reoperated with bony decompression and stabilization. Six $(1 \%)$ other complications were also reported (infections and postoperative leakages).

\section{Discussion}

The literature has been systematically reviewed to evaluate the outcome for patients with intermittent neurogenic claudication treated with IPD versus bony decompression or conservative non-surgical treatment. To our knowledge, this is the first systematic review and meta-analysis on this subject. After a literature search, two independent RCTs and eight prospective cohorts, one with a control group, were eligible for validation and data extraction. The methodological quality of the RCTs were 5 (Zucherman) and 6 (Anderson) $[17,21]$. The methodological quality of the remaining prospective cohort studies was relatively low (only one reached 6 out of 8) [22, 70-76]. In total 563 patients were treated with IPD. All studies showed improvement in validated outcome scores after 6 weeks and 1 year. Pooled data of the RCTs were more in favor of IPD treatment compared with conservative treatment.

The review of the literature showed that very little is known about treatment with IPD. Only one comparative study with good methodological quality fulfilling our selection criteria was found [21]. Different indications are used for these devices, such as described by Richter who used an IPD in combination with surgical decompression [22]. Some studies show beneficial effect of surgical technique compared to conservative treatment for patients with degenerative lumbar spinal stenosis and neurogenic intermittent claudication $[10,11]$. More centers, however, 


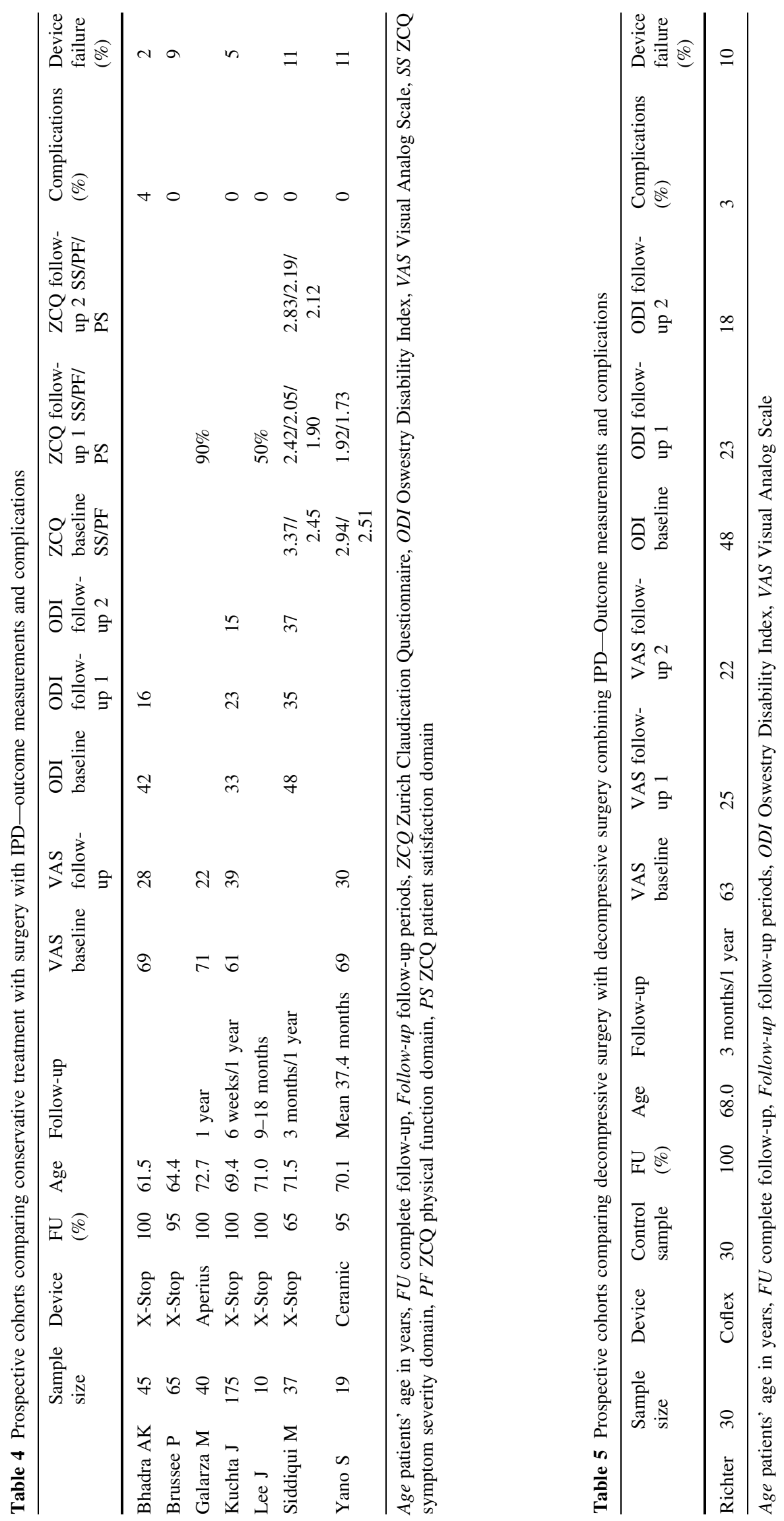




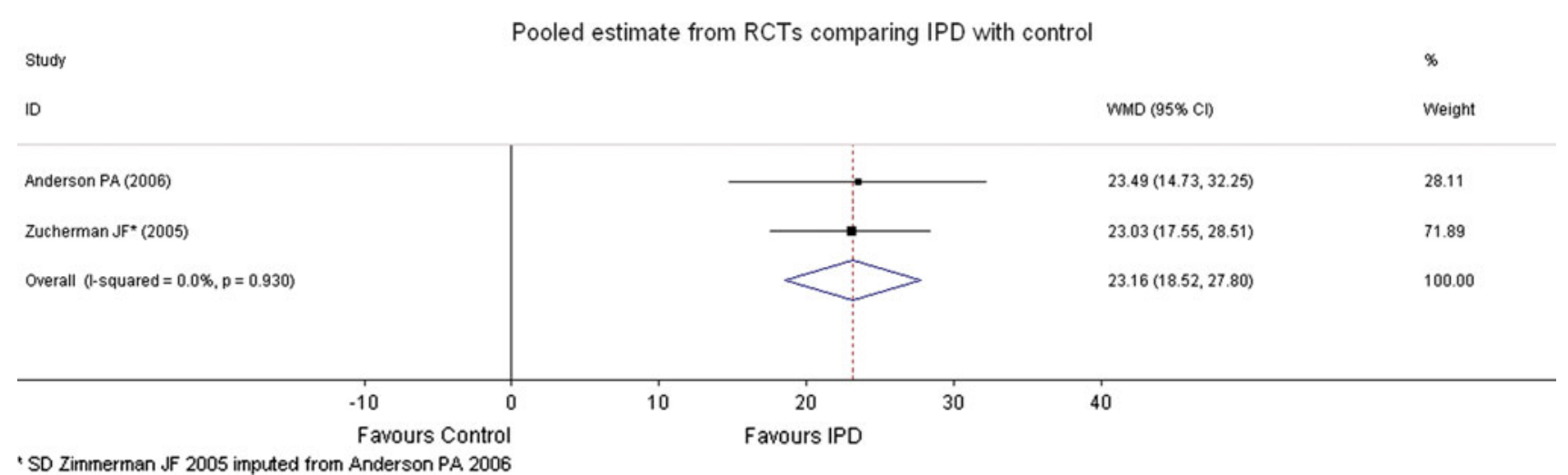

Fig. 2 Meta-analysis. IPD interspinous process decompression, $S D$ standard deviation, $W M D$ weighted mean difference

perform complex techniques rather than only a decompression technique. Between 2002 and 2007, complex fusion procedures showed a 15-fold increase in the USA. Furthermore, the overall procedure rate slightly decreased with $1.4 \%$ [77-79]. Coflex worldwide implants increased from 1,717 in 2005 to 13,128 in 2009 . Even without evidence of implantation of an IPD as a treatment strategy for INC, some centers use it in a combination with other techniques [22]. Despite the fact that no arguments exist in the literature about the effectiveness of treatment with IPD versus bony decompression, many centers throughout the world use IPD for the treatment of INC.

Overall complication and failure rate of $(7 \%$, including $6 \%$ reoperations rate after device failure) tended to be relatively low compared to the complication rate of standard bony decompression. For example, Weinstein and Malmivaara [10, 11] reported a complication rate of $17-24 \%$ in the standard bony decompression operation cohorts. The most frequently reported complications in these series are dural tears and wrong level surgery. Due to the use of standard X-rays in the operation theater with IPD treatment, wrong level surgery in interspinous decompression surgery is rare. Most techniques of interspinous decompression are indirect and with some distance from the dura, therefore causing a dural tear is difficult by regular surgical methods. Despite the large numbers of case reports on complications after IPD treatment, complication rates tends to be low $[43,44,80,81]$. This, however, might be induced by selection bias of published studies. Despite the relatively low complication rate, device failure rate needing reoperation is high $(6 \%)$. This number can be higher because of the publication bias, but also the lack of long-term follow-up. This conclusion is difficult to confirm due to the fact that no comparative studies are done on this subject. Combined with the $6 \%$ device failure rate complication rate, the IPD complication rate is $7 \%$. In the literature, implantation surgery is associated with complication rate of $8 \%$ (2-6\% failure rate) [79]. The complication rate would be possible higher when complications would be monitored 30 days after discharge. Not all studies included in our review reported complication rate 30 days after hospital stay. Prospective reporting of complication should be made standard in future trials.

The most important limitation of this review concerned the methodological weaknesses and selection biases of the included studies: the vast majority was observational, without independent outcome assessment, and without complications well defined. Additionally, we combined two different RCTs for our meta-analysis [17, 21]. Both studies did not mention a thorough power or sample size design, resulting in a 191 patients in one RCT and 75 in the other. Furthermore, only one study was of relatively high methodological quality. Therefore, possible information bias could be introduced. Furthermore we excluded 242 studies, introducing selection bias. Due to the retrospective design of some of these studies, possible interesting patient data had to be excluded. Studies that were published in abstract or poster format only were excluded. The present study was aimed at identifying published peer-reviewed literature, so that influence of publication bias cannot be ruled out. Due to the small number of studies, possible publication bias (using e.g. funnel plot) could not adequately be assessed. Due to the anticipated low number of RCTs, prospective studies were also included. Most of these studies were of low methodological quality (Table 2, Validation). Due to the inclusion of studies of low methodological quality, information bias is easily introduced. Furthermore, methodological quality assessment does not take into account the author's disclosure. For example, two studies in our review stated that one of the authors is a consultant and, in one article, stockholder of the company manufacturing the IPD device they were using for their study $[21,70]$. The remaining studies did not mention any conflict of interest or disclosure. Seven studies did not even describe the possible conflicts of interest. Assessing possible conflict of interest is not incorporated in both 
validation scales [25, 27]. Standard adjusting both scales based on possible conflict of interest is advisable.

This review of the literature shows that surgical decompression with interspinous process devices is superior to conservative non-surgical treatment in patients with lumbar degenerative spinal stenosis with INC. However, the level of evidence for this conclusion is debatable due to the low quality of some of the included studies. Furthermore, no data is presently available comparing interspinous process decompression with standard bony decompression. We suggest that more studies will be done on this subject comparing the surgical treatment with IPD versus bony decompression. Despite the fact that we could give a Grade A recommendation, according to the Oxford-Centre for Evidence Based Medicine, we suggest that further studies have to be performed before a thorough recommendation can be given regarding the treatment of INC with IPDs [82]. These studies should also include analysis on complication rate and device failure rate. As the evidence is relatively low and the costs are high, more thorough cost-effectiveness studies should be performed before worldwide implementation is introduced. Because the golden standard for surgical decompression seems to be absent, patients with lumbar spinal stenosis should be guarded against instrumented surgery or the use of IPD on the basis of the current evidence.

Acknowledgments The authors did not receive any funding.

Conflict of interest The authors have no conflict of interest.

Open Access This article is distributed under the terms of the Creative Commons Attribution Noncommercial License which permits any noncommercial use, distribution, and reproduction in any medium, provided the original author(s) and source are credited.

\section{References}

1. Johnsson KE, Uden A, Rosen I (1991) The effect of decompression on the natural course of spinal stenosis. A comparison of surgically treated and untreated patients. Spine (Phila Pa 1976) 16:615-619

2. Amundsen $\mathrm{T}$, Weber $\mathrm{H}$, Lilleas $\mathrm{F}$, Nordal HJ, Abdelnoor M, Magnaes B (1995) Lumbar spinal stenosis. Clinical and radiologic features. Spine (Phila Pa 1976) 20:1178-1186

3. Gibson JN, Grant IC, Waddell G (1999) The Cochrane review of surgery for lumbar disc prolapse and degenerative lumbar spondylosis. Spine (Phila Pa 1976) 24:1820-1832

4. Gibson JN, Waddell G (2005) Surgery for degenerative lumbar spondylosis: updated Cochrane review. Spine (Phila Pa 1976) 30:2312-2320

5. EVANS JG (1964) Neurogenic intermittent claudication. Br Med J 2:985-987

6. Verbiest H (1950) Primary stenosis of the lumbar spinal canal in adults, a new syndrome. Ned Tijdschr Geneeskd 94:2415-2433

7. Verbiest H (1951) Further reports on primary stenosis of the lumbar spinal canal in adults. Ned Tijdschr Geneeskd 95:1965-1970
8. Verbiest H (1954) A radicular syndrome from developmental narrowing of the lumbar vertebral canal. J Bone Joint Surg Br 36-B:230-237

9. Arnoldi CC, Brodsky AE, Cauchoix J et al (1976) Lumbar spinal stenosis and nerve root entrapment syndromes. Definition and classification. Clin Orthop Relat Res 115:4-5

10. Malmivaara A, Slatis P, Heliovaara M et al (2007) Surgical or nonoperative treatment for lumbar spinal stenosis? A randomized controlled trial. Spine (Phila Pa 1976) 32:1-8

11. Weinstein JN, Tosteson TD, Lurie JD et al (2008) Surgical versus nonsurgical therapy for lumbar spinal stenosis. N Engl J Med 358:794-810

12. Thome C, Zevgaridis D, Leheta O et al (2005) Outcome after less-invasive decompression of lumbar spinal stenosis: a randomized comparison of unilateral laminotomy, bilateral laminotomy, and laminectomy. J Neurosurg Spine 3:129-141

13. Mariottini A, Pieri S, Giachi S et al (2005) Preliminary results of a soft novel lumbar intervertebral prothesis (DIAM) in the degenerative spinal pathology. Acta Neurochir Suppl 92:129-131

14. Tsai KJ, Murakami H, Lowery GL, Hutton WC (2006) A biomechanical evaluation of an interspinous device (Coflex) used to stabilize the lumbar spine. J Surg Orthop Adv 15:167-172

15. Simons P, Werner D, Krause P, Mark P, Godde G, Reinhard A (2006) Treatment of neurogenic intermittent claudication (NIC), secondary to lumbar spinal stenosis (LSS), with the COFLEX ${ }^{\circledR}$ Interspinous Process Decompression (IPD) system. Early ZCQ outcome results from the European registry

16. Wilke HJ, Drumm J, Haussler K, Mack C, Steudel WI, Kettler A (2008) Biomechanical effect of different lumbar interspinous implants on flexibility and intradiscal pressure. Eur Spine J 17:1049-1056

17. Zucherman JF, Hsu KY, Hartjen CA et al (2004) A prospective randomized multi-center study for the treatment of lumbar spinal stenosis with the X STOP interspinous implant: 1-year results. Eur Spine J 13:22-31

18. Siddiqui M, Karadimas E, Nicol M, Smith FW, Wardlaw D (2006) Influence of X Stop on neural foramina and spinal canal area in spinal stenosis. Spine (Phila Pa 1976) 31:2958-2962

19. Siddiqui M, Karadimas E, Nicol M, Smith FW, Wardlaw D (2006) Effects of X-STOP device on sagittal lumbar spine kinematics in spinal stenosis. J Spinal Disord Tech 19:328-333

20. Sale numbers directly obtained from Kyphon Inc and Paradigm Spine Inc

21. Anderson PA, Tribus CB, Kitchel SH (2006) Treatment of neurogenic claudication by interspinous decompression: application of the X STOP device in patients with lumbar degenerative spondylolisthesis. J Neurosurg Spine 4:463-471

22. Richter A, Schutz C, Hauck M, Halm H (2009) Does an interspinous device (Coflex) improve the outcome of decompressive surgery in lumbar spinal stenosis? One-year follow up of a prospective case control study of 60 patients. Eur Spine J 19(2):283-289

23. Zucherman JF, Hsu KY, Hartjen CA et al (2005) A multicenter, prospective, randomized trial evaluating the X STOP interspinous process decompression system for the treatment of neurogenic intermittent claudication: two-year follow-up results. Spine (Phila Pa 1976) 30:1351-1358

24. Stromqvist B, Johnsson R, Sahlstrand T, Tullberg T (2007) Comparison of patients with neurogenic intermittent claudication treated with the X-Stop interspinous process decompression system vs decompressive surgery-early follow-up results. Spine J 5:S168

25. Furlan JC, Singh J, Hsieh J, Fehlings MG (2010) Methodology of systematic reviews and recommendations. J Neurotrauma [Epub ahead of print]

26. Stroup DF, Berlin JA, Morton SC et al (2000) Meta-analysis of observational studies in epidemiology: a proposal for reporting. 
Meta-analysis Of Observational Studies in Epidemiology (MOOSE) group. JAMA 283:2008-2012

27. van Tulder M, Furlan A, Bombardier C, Bouter L (2003) Updated method guidelines for systematic reviews in the cochrane collaboration back review group. Spine (Phila $\mathrm{Pa}$ 1976) 28:1290-1299

28. Deyo RA (1986) Comparative validity of the sickness impact profile and shorter scales for functional assessment in low-back pain. Spine (Phila Pa 1976) 11:951-954

29. Deyo RA, Diehl AK (1986) Patient satisfaction with medical care for low-back pain. Spine (Phila Pa 1976) 11:28-30

30. Deyo RA, Patrick DL (1995) The significance of treatment effects: the clinical perspective. Med Care 33:AS286-AS291

31. Hutchinson PJ, Laing RJ, Waran V, Hutchinson E, Hollingworth W (2000) Assessing outcome in lumbar disc surgery using patient completed measures. Br J Neurosurg 14:195-199

32. Koes BW, van Tulder MW, Thomas S (2006) Diagnosis and treatment of low back pain. BMJ 332:1430-1434

33. Patrick DL, Deyo RA (1989) Generic and disease-specific measures in assessing health status and quality of life. Med Care 27:S217-S232

34. Patrick DL, Deyo RA, Atlas SJ, DE Singer, Chapin A, Keller RB (1995) Assessing health-related quality of life in patients with sciatica. Spine (Phila Pa 1976) 20:1899-1908

35. Pratt RK, Fairbank JC, Virr A (2002) The reliability of the Shuttle Walking Test, the Swiss Spinal Stenosis Questionnaire, the Oxford Spinal Stenosis Score, and the Oswestry Disability Index in the assessment of patients with lumbar spinal stenosis. Spine (Phila Pa 1976) 27:84-91

36. Roland M, Morris R (1983) A study of the natural history of lowback pain. Part II: development of guidelines for trials of treatment in primary care. Spine (Phila Pa 1976) 8:145-150

37. Roland M, Morris R (1983) A study of the natural history of back pain. Part I: development of a reliable and sensitive measure of disability in low-back pain. Spine (Phila Pa 1976) 8:141-144

38. Stucki G, Liang MH, Fossel AH, Katz JN (1995) Relative responsiveness of condition-specific and generic health status measures in degenerative lumbar spinal stenosis. J Clin Epidemiol 48:1369-1378

39. Stucki G, Daltroy L, Liang MH, Lipson SJ, Fossel AH, Katz JN (1996) Measurement properties of a self-administered outcome measure in lumbar spinal stenosis. Spine (Phila $\mathrm{Pa}$ 1976) 21:796-803

40. Oxman AD, Guyatt GH (1991) Validation of an index of the quality of review articles. J Clin Epidemiol 44:1271-1278

41. Verhagen AP, de Vet HC, de Bie RA, Boers M, van den Brandt PA (2001) The art of quality assessment of RCTs included in systematic reviews. J Clin Epidemiol 54:651-654

42. Furlan AD, Pennick V, Bombardier C, van TM (2009) Updated method guidelines for systematic reviews in the Cochrane Back Review Group. Spine (Phila Pa 1976) 34:1929-1941

43. Barbagallo GM, Olindo G, Corbino L, Albanese V (2009) Analysis of complications in patients treated with the X-Stop interspinous process decompression system: proposal for a novel anatomic scoring system for patient selection and review of the literature. Neurosurgery 65:111-119

44. Bowers C, Amini A, Dailey AT, Schmidt MH (2010) Dynamic interspinous process stabilization: review of complications associated with the X-Stop device. Neurosurg Focus 28(6):E8

45. La Marca F (2009) Analysis of complications in patients treated with the X-Stop interspinous process decompression system: Proposal for a novel anatomic scoring system for patient selection and review of the literature - Commentary. Neurosurgery $65: 120$

46. Resnick DK (2009) Analysis of complications in patients treated with the $\mathrm{X}$-Stop interspinous process decompression system: proposal for a novel anatomic scoring system for patient selection and review of the literature-commentary. Neurosurgery 65:119

47. Tuli SK, Yerby SA, Katz JN (2006) Methodological approaches to developing criteria for improvement in lumbar spinal stenosis surgery. Spine (Phila Pa 1976) 31:1276-1280

48. Schoppink LE, van Tulder MW, Koes BW, Beurskens SA, de Bie RA (1996) Reliability and validity of the Dutch adaptation of the Quebec Back Pain Disability Scale. Phys Ther 76:268-275

49. Carlsson AM (1983) Assessment of chronic pain I. Aspects of the reliability and validity of the visual analogue scale. Pain 16:87-101

50. Phelan EA, Deyo RA, Cherkin DC et al (2001) Helping patients decide about back surgery: a randomized trial of an interactive video program. Spine (Phila Pa 1976) 26:206-211

51. Fairbank JC, Couper J, Davies JB, O'Brien JP (1980) The Oswestry low back pain disability questionnaire. Physiotherapy 66:271-273

52. Copay AG, Subach BR, Glassman SD, Polly DW Jr, Schuler TC (2007) Understanding the minimum clinically important difference: a review of concepts and methods. Spine J 7:541-546

53. Copay AG, Glassman SD, Subach BR, Berven S, Schuler TC, Carreon LY (2008) Minimum clinically important difference in lumbar spine surgery patients: a choice of methods using the Oswestry Disability Index, Medical Outcomes Study questionnaire Short Form 36, and pain scales. Spine J 8:968-974

54. Hsu KY, Zucherman JF, Hartjen CA et al (2006) Quality of life of lumbar stenosis-treated patients in whom the X STOP interspinous device was implanted. J Neurosurg Spine 5:500-507

55. Kondrashov DG, Hannibal M, Hsu KY, Zucherman JF (2006) Interspinous process decompression with the X-STOP device for lumbar spinal stenosis: a 4-year follow-up study. J Spinal Disord Tech 19:323-327

56. Collignon F, Fransen P (2010) Treatment of symptomatic degenerative lumbar spinal stenosis by a percutaneous standalone lumbar interspinous implant. Preliminary experience with the Aperius device. Neurochirurgie 56:3-7

57. Hrabalek L, Machac J, Vaverka M (2009) The DIAM spinal stabilisation system to treat degenerative disease of the lumbosacral spine. Acta Chir Orthop Traumatol Cech 76:417-423

58. Hsu K, Zucherman J, Hartjen C et al (2004) Interspinous process decompression (IPD) significantly improves symptom severity in neurogenic intermittent claudication patients. Spine J 4:S60

59. Implicito D, Martin M, Ozuna R (2007) Outcomes of neurogenic intermittent claudication patients treated with interspinous decompression as a function of number of levels treated. Spine $\mathrm{J}$ 5:S90

60. Kondrashov D, Hannibal M, Hsu K, Zucherman J (2006) The X STOP interspinous process decompression versus laminectomy for treatment of lumbar spinal stenosis: economic analysis. Neurosurgery 59:458

61. Skidmore G, Ackerman S, Bergin C et al (2009) Cost-effectiveness of interspinous process decompression for lumbar spinal stenosis: a comparison with conservative care and laminectomy. Spine J 7:95S

62. Zucherman J, Hsu K, Hartjen C et al (2004) A prospective randomized multicenter study of lumbar neurogenic intermittent claudication patients treated conservatively with a laminectomy or with interspinous process decompression. The Spine Journal 4:S33-S34

63. Zucherman J, Hsu K, Wahlig J, Hartjen C, Shabe P, Tillman J (2009) Five year outcomes in patients treated with the X-STOP interspinous process device for neurogenic intermittent claudication due to lumbar spinal stenosis. Spine J 8:153S

64. Eichholz KM, Fessler RG (2006) Is the X STOP interspinous implant a safe and effective treatment for neurogenic intermittent claudication? Nat Clin Pract Neurol 2:22-23 
65. Weiner BK, Zucherman JF, Hsu KY, Hartjen CA. A multicenter, prospective, randomized trial evaluating the X STOP interspinous process decompression system for the treatment of neurogenic intermittent claudication: Two-year follow-up results. Spine 2005; 30:1351-1358, 2846-2847

66. Errico TJ, Kamerlink JR, Quirno M, Samani J, Chomiak RJ (2009) Survivorship of coflex Interlaminar-Interspinous Implant. SAS J 3:59-67

67. Nardi P, Cabezas D, Rea G, Pettorini BL (2010) Aperius PercLID stand alone interspinous system for the treatment of degenerative lumbar stenosis: experience on 152 cases. J Spinal Disord Tech 23(3):203-207

68. Senegas J, Vital JM, Pointillart V, Mangione P (2009) Clinical evaluation of a lumbar interspinous dynamic stabilization device (the Wallis system) with a 13-year mean follow-up. Neurosurg Rev 32:335-341

69. Verhoof OJ, Bron JL, Wapstra FH, van Royen BJ (2008) High failure rate of the interspinous distraction device (X-Stop) for the treatment of lumbar spinal stenosis caused by degenerative spondylolisthesis. Eur Spine J 17:188-192

70. Bhadra AK, Raman AS, Tucker S, Noordeen HH (2008) Interspinous implant in lumbar spinal stenosis: a prospective cohort. Eur J Orthop Surg Traumatol 18:489-493

71. Brussee P, Hauth J, Donk RD, Verbeek AL, Bartels RH (2008) Self-rated evaluation of outcome of the implantation of interspinous process distraction (X-Stop) for neurogenic claudication. Eur Spine J 17:200-203

72. Galarza M, Fabrizi AP, Maina R, Gazzeri R, Martinez-Lage JF (2010) Degenerative lumbar spinal stenosis with neurogenic intermittent claudication and treatment with the Aperius PercLID System: a preliminary report. Neurosurg Focus 28(6):E3

73. Kuchta J, Sobottke R, Eysel P, Simons P (2009) Two-year results of interspinous spacer (X-Stop) implantation in 175 patients with neurologic intermittent claudication due to lumbar spinal stenosis. Eur Spine J 18:823-829

74. Lee J, Hida K, Seki T, Iwasaki Y, Minoru A (2004) An interspinous process distractor (X STOP) for lumbar spinal stenosis in elderly patients: preliminary experiences in 10 consecutive cases. J Spinal Disord Tech 17:72-77

75. Siddiqui M, Smith FW, Wardlaw D (2007) One-year results of X Stop interspinous implant for the treatment of lumbar spinal stenosis. Spine (Phila Pa 1976) 32:1345-1348

76. Yano S, Hida K, Seki T, Aoyama T, Akino M, Iwasaki Y (2008) A new ceramic interspinous process spacer for lumbar spinal canal stenosis. Neurosurgery 63:ONS108-ONS113

77. Carragee EJ (2010) The increasing morbidity of elective spinal stenosis surgery: is it necessary? JAMA 303:1309-1310

78. Deyo RA, Gray DT, Kreuter W, Mirza S, Martin BI (2005) United States trends in lumbar fusion surgery for degenerative conditions. Spine (Phila Pa 1976) 30:1441-1445

79. Deyo RA, Mirza SK, Martin BI, Kreuter W, Goodman DC, Jarvik JG (2010) Trends, major medical complications, and charges associated with surgery for lumbar spinal stenosis in older adults. JAMA 303:1259-1265

80. Barbagallo GM, Corbino LA, Olindo G, Foti P, Albanese V, Signorelli F (2010) The "sandwich phenomenon": a rare complication in adjacent, double-level X-stop surgery: report of three cases and review of the literature. Spine (Phila Pa 1976) 35:E96E100

81. Epstein NE (2009) X-Stop: foot drop. Spine J 9:e6-e9

82. Phillips B, Ball C, Sackett DL et al (1998) Levels of evidence and grades of recommendation. Centre for Evidence-Based Medicine: Oxford-Centre for Evidence Based Medicine 